\title{
Tumor Antigen Response
}

National Cancer Institute

\section{Source}

National Cancer Institute. Tumor Antigen Response. NCI Thesaurus. Code C123628.

An evaluation of the change in tumor antigen quantity in response to the therapy. 